\title{
NEM MOCHO, NEM COTOVIA
}

\section{CAMILA VALCANOVER*}

Universidade Presbiteriana Mackenzie (UPM), Programa de Pós-Graduação em Letras (PPGL), São Paulo, SP, Brasil.

Recebido em: 18 dez. 2020. Aprovado em: 7 mar. 2021.

Como citar este artigo: VALCANOVER, C. Nem mocho, nem cotovia. Cadernos de Pós-Graduação em Letras, v. 21, n. 1, p. 123-134, jan./abr. 2021. doi: 10.5935/cadernosletras.v21n1p123-134

\section{Resumo}

Neste artigo, propomo-nos a percorrer a afirmação de Calvino (2004) que, ao organizar a seleção Contos fantásticos do século XIX, apresenta o conto "A noite", de Guy de Maupassant, como "Um exemplo de Fantástico obtido com mínimos recursos". Os estudos de Todorov (2017) e Ceserani (2006) nos ajudam a compreender a arquitetura do texto de Maupassant, revelando como as características teóricas aparecem, nesse caso, diluídas no texto literário.

\section{Palavras-chave}

Conto. Fantástico. Século XIX.

* E-mail: camilavalcanover@gmail.com

(D) https://orcid.org/0000-0002-3319-3844 
Uma espécie de estranhamento sente o leitor ao finalizar "A noite", de Guy de Maupassant. O estranhamento surge porque pouco se sabe desse universo ficcional: o narrador autodiegético não é nomeado, não temos características físicas desse homem (o gênero é marcado pela flexão de alguns substantivos) e sabemos que o evento narrado/experienciado ocorre no período da noite, em Paris. Todo o restante faz parte do universo ficcional psicológico e psicótico criado por Maupassant e inserido no subconsciente do narrador. $\mathrm{O}$ conto é uma espécie de monólogo interior, um contínuo fluxo de (in)consciência em que o narrador percorre os labirintos do sonho e do devaneio.

A narração em primeira pessoa e o envolvimento do leitor implícito adotados por Maupassant são apontados por Remo Ceserani (2006) e Tzvetan Todorov (2017) como procedimentos narrativos e retóricos muito utilizados pela literatura fantástica, que "autenticam ao máximo a ficção narrativa e estimulam e facilitam o ato de identificação do leitor implícito com o leitor externo do texto" (CESERANI, 2006, p. 69). Todorov (2017, p. 94) ressalta: "nas melhores novelas fantásticas, Maupassant faz do narrador o próprio herói da história”.

O conto inicia-se com uma declaração de amor à noite: "Amo a noite apaixonadamente" (MAUPASSANT, 2004, p. 221). A inserção do advérbio "apaixonadamente" revela o modo como esse amor se realiza, o que justifica a angústia do narrador ao longo do conto, quando percebe que a paixão rapidamente se desgasta. O que se segue à declaração de amor é a sua intensidade: o narrador ama a noite "como quem ama o seu país ou a sua amante [...]" (MAUPASSANT, 2004, p. 221). O narrador coloca no mesmo patamar: noite-pátria-mulher amada.

Convém lembrarmos o contexto em que a produção de Maupassant está inserida: após os tumultos da guerra franco-prussiana (1870-1871), que depôs o imperador Napoleão III em 1870, entrou em vigor a Terceira República Francesa (1870-1940), primeiro regime durável após a revolução de 1789. Retornando ao conto de Maupassant, observa-se a importância que o narrador concede à noite, ao amá-la como um francês ama sua pátria.

Nos primeiros parágrafos, o narrador personifica a noite, revelando uma espécie de prazer carnal que esse amor lhe dá, um caráter lascivo, voluptuoso: "Então sinto vontade de gritar de prazer como as corujas, de correr pelos telhados como os gatos; e um desejo de amar, impetuoso, invencível, arde em minhas veias. [...]. O que amamos com violência sempre acaba nos matando" 
(MAUPASSANT, 2004, p. 221). É nessa obnubilação, no limite entre realidade e ficção, que o leitor se situa, acompanhando um narrador-personagem que ele, leitor, nem sabe o nome.

O envolvimento do leitor é outra característica apontada por Ceserani (2006, p. 71): “O conto fantástico envolve fortemente o leitor, leva-o para dentro de um mundo a ele familiar, aceitável, pacífico, para depois fazer disparar os mecanismos da surpresa, da desorientação, do medo [...]”. É esse envolvimento que prende o leitor na narração das "quase ações" sucedidas.

Aspecto fundamental para entendermos a construção desse espaço-tempo ficcional é o apelo à sinestesia, desde as primeiras linhas. O narrador convida o leitor a sentir a noite: visão, olfato, audição e tato. A experiência notívaga é construída além do signo verbal.

Ainda no início do conto, o narrador faz a oposição entre elementos que caracterizam a noite que tanto ama e o dia que o cansa e o aborrece. A noite é descrita com amor e intensidade, com palavras que revelam a paixão do narrador, enquanto as palavras que descrevem o dia estão em campo semântico oposto: cansaço, aborrece, brutal, barulhento, contragosto, preguiça, lassidão e fardo. Ao descrever o dia, o narrador reitera a rejeição por esse período, criando uma tensão e um enaltecimento a esse horror: "cada passo, cada movimento, cada gesto, cada palavra, cada pensamento me cansa como se eu levantasse um fardo que me esmagasse” (MAUPASSANT, 2004, p. 221). A anáfora criada com a repetição do vocábulo "cada” cria uma espécie de gradação, em que o narrador parte de uma perspectiva ampla (passo, movimento) para uma perspectiva mais íntima (gesto, palavra, pensamento). A comparação ao final do período resume toda a angústia que o dia lhe causa: "como seu eu levantasse um fardo", que o destrói: “me esmagasse”. A imagem da opressão do dia é reiteradamente exposta ao leitor.

A oposição entre o dia e a noite se encontra, inclusive, nos elementos figurativos que o narrador usa para ilustrar suas preferências: o mocho, ave de hábitos noturnos, de comportamento predatório com voo silencioso e preciso, opondo-se à cotovia, ave de hábitos diurnos que tem o canto como característica. Outro par que atua na construção da predileção pela noite é o gato e a coruja, ambos caçadores, ambos animais de hábitos noturnos que têm na escuridão uma aliada. Ceserani (2006, p. 78), ao apresentar os sistemas temáticos recorrentes na literatura fantástica, aponta a noite e a oposição entre claro e o escuro como um dos núcleos temáticos: "A contraposição entre o claro e o 
escuro, sol e escuridão noturna é bastante utilizada no fantástico", algo que é inteiramente encontrado no texto literário de Maupassant.

Ceserani (2006, p. 70) aponta para "Um forte interesse pela capacidade criativa e projetiva da linguagem" como um dos procedimentos narrativos e retóricos do fantástico: “O modo fantástico utiliza profundamente as potencialidades fantasiosas da linguagem, a sua capacidade de carregar de valores plásticos as palavras e formar a partir delas uma realidade”. Encontraremos em "A noite" inúmeras passagens que ilustram a capacidade criativa e projetiva da linguagem, permitindo a criação do espaço-tempo da narrativa na intersecção entre o real e o imaginário.

$\mathrm{O}$ narrador demora para situar o leitor sobre o espaço onde esse amor à noite ocorre: Paris. Munido com um mapa, o leitor poderá trilhar o caminho percorrido e perceberá que a confusão e angústia do narrador percorrem vários bairros às margens do rio Sena, onde rondam “as minhas irmãs, as bestas, e os meus irmãos, os caçadores clandestinos” (MAUPASSANT, 2004, p. 221), novamente o recurso da ilustração é utilizado. É nesse universo ocupado por bestas e caçadores, criaturas das trevas, que o personagem do conto transita e leva o leitor. O trajeto familiar e as imagens cotidianas construirão o sentimento de terror. A georreferenciação de Paris mostra os lampejos de realidade que o narrador possui.

O espaço literário em "A noite" assume a posição de "articulador da história", não podendo ser encarado como um elemento decorativo no texto, muito pelo contrário, uma vez que pode vir a ser o responsável pela ampliação dos sentidos do texto, sempre considerando sua atuação em conjunto e em estreita relação com os demais elementos constituintes da arquitetura literária. Em ensaio que é parte integrante de obra dedicada a análises que tematizam o espaço na literatura, Barbieri (2009, p. 105) considera que

A construção espacial da narrativa deixa de ser passiva - enquanto um elemento necessário apenas à contextualização e pano de fundo para os acontecimentos - e passa a ser um agente ativo: o espaço, o lugar como articulador da história. A percepção deste pela personagem e seu percurso dão ao leitor uma maior compreensão da constituição de ambos e ampliam as possibilidades de significação do texto.

"A noite" pode ser dividida, didaticamente, em três partes: a primeira, que apresentamos até este momento, engloba os cinco primeiros parágrafos, em que o narrador declara seu amor pela noite; a segunda parte do conto, em 
nossa proposta, se inicia no sexto parágrafo, quando o narrador começa a demonstrar certa confusão mental e narra seu devaneio, transformando a noite, até então amada, em algo aterrorizante; a terceira parte abarca os quatro últimos parágrafos, quando o narrador parece recuperar a consciência. Assim, retomaremos a análise do que denominamos segunda parte.

A segunda parte de "A noite" traz algumas marcações que permitem que o leitor se localize no espaço-tempo que começará a ser construído. No sexto parágrafo, o narrador é taxativo ao afirmar: "O que amamos com violência sempre acaba nos matando" (MAUPASSANT, 2004, p. 221). Nesse momento, dá uma pista da possível dissolução do conto: a morte. Ou o que sente pela noite não é, necessariamente, amor. Está instaurado o jogo dialético entre amor e violência. É nesse momento da narrativa que a confusão do narrador começa a transparecer.

O leitor, se desatento, pode não perceber a antecipação da resolução do conto, quando o narrador afirma: "Mas como explicar o que acontece comigo? E, mesmo, como explicar que sou capaz de contá-lo?” (MAUPASSANT, 2004, p. 221), ou seja, o personagem não morre às margens do Sena de fome, frio ou cansaço, ele sobreviveu (ou acordou) para narrar o episódio. Outro efeito que essa afirmação causa é a criação da expectativa de que alguma ação tenha ocorrido; afinal, se há algo para contar, é porque há alguma peripécia, algum desdobramento desse titubeio. A história narrada dentro do pesadelo do narrador que sonha com sua morte (ou quase morte) é o que gera a experiência fantástica do conto.

A confusão temporal em decorrência do evento a ser narrado é reiterada quando o narrador se questiona: "Portanto, ontem - era ontem?" (MAUPASSANT, 2004, p. 221). Nessa passagem há mais uma prova de vida do narrador: sim, ele sobreviveu às margens do Sena para contar o que se passou ontem ou em outro dia qualquer. O que a seguir é confirmado: "Assim, ontem saí, como faço todas as noites, depois do jantar" (MAUPASSANT, 2004, p. 221). A ambiguidade é sugerida pela linguagem, criativa e projetiva, de acordo com Ceserani (2006), e pela pontuação expressiva: o uso de reticências e interrogações materializa a vibração psicológica, a oscilação entre a irrupção do inconsciente e o recobrar da consciência, evidenciando a realidade psíquica da experiência a ser narrada.

Em alguns parágrafos anteriores, fizemos referência ao contexto histórico no momento da escrita do conto "A noite". É importante também destacar a presença da modernização de Paris, uma das fontes que promovem a oscilação 
dos níveis de realidade em que o narrador se situa: "No ar leve, tudo estava claro, desde os planetas até os bicos de gás. Tantas luzes brilhavam lá no alto e na cidade que as trevas pareciam luminosas. As noites luzentes são mais alegres que os grandes dias de sol" (MAUPASSANT, 2004, p. 222). A ansiedade gerada pelo lusco-fusco dos bicos de gás que iluminam as ruas de Paris, de modo metafórico, revela a ansiedade criada pela industrialização, é quando o inquietante vivido se reflete no inquietante ficcional. A utilização dos bicos de gás, simbolizando a modernidade de Paris, é apontada por Ceserani (2006) ao apresentar a figuratividade como um dos procedimentos retóricos e narrativos do fantástico, sublinhando como recurso temático e semântico, fundamental para o fantástico mental ou abstrato.

O uso da metáfora, citada no parágrafo anterior, como recurso retórico narrativo é também apontado por Ceserani (2006, p. 71) como uma forma de "permitir aquelas repentinas e inquietantes passagens de limite e de fronteira, que são características fundamentais da narrativa fantástica”. São as passagens entre realidade e ilusão, quando o sonho/pesadelo como manifestação da mente humana pode resguardar uma vertente do fantástico, quando ocorre a transição do ambiente familiar, costumeiro para o ambiente perturbador, podendo ser do sonho, da loucura ou do pesadelo: "O personagem protagonista se encontra repentinamente como se estivesse dentro de duas dimensões diversas, com códigos diversos à sua disposição, para orientar-se ou compreender" (CESERANI, 2006, p. 73). Ao abordar os sistemas temáticos recorrentes na literatura fantástica, Ceserani (2006, p. 83) aponta que "A loucura, como fenômeno patológico e social, tinha uma presença forte e, enquanto fenômeno cultural e tema literário, uma longa tradição".

A presença vívida nos bulevares causa agonia, novamente temos a oposição de campos semânticos para descrever a vibração da Champs-Elysées e a melancolia sentida pelo narrador:

Lá dentro estava tão claro que me senti agoniado e saí com o coração meio obscurecido por aquele choque brutal de luz nos dourados do balcão, pelo cintilar fictício do enorme lustre de cristal, pela cortina de luzes da ribalta, pela melancolia daquela claridade falsa e crua. Cheguei a Champs-Elysées, onde os cafés-concertos pareciam focos de incêndio no meio das folhagens. [...] E os globos de luz elétrica, parecendo luas cintilantes e pálidas, ovos de lua caídos do céu, pérolas monstruosas, vivas, faziam empalidecer, sob sua claridade nacarada, misteriosa e imperial, os fios de gás, do feio gás sujo [...] (MAUPASSANT, 2004, p. 222). 
Nessa longa citação, percebemos o trajeto criado pelo narrador: do racional (acordado) para o irracional (adormecido), quando é visitado pelo insólito, quando o subnatural, a interioridade do indivíduo cria um plano paralelo, dominado pelo soturno, obscuro e solitário em que: "desenham essas figuras estranhas que tanto fazem sonhar, que tanto fazem pensar" (MAUPASSANT, 2004, p. 222). Nessa passagem, percebemos o despertar da consciência, reflexão resultante da narração de memória, pois, como já destacamos, o evento narrado já ocorreu.

Ao progredir pelo "passeio" em Paris e chegar ao Bois de Boulogne, nesse momento, percebemos a mudança de atmosfera: "A cidade adormecia, e nuvens, grossas nuvens pretas, espalhavam-se lentamente no céu” (MAUPASSANT, 2004, p. 222), é anunciada a mudança nas percepções do narrador. O desaparecimento da ordem natural do tempo anuncia a entrada no fantástico. Os múltiplos sentidos do narrador influenciam na percepção sobre o espaço. Lins (1976, p. 92) explora os modos de percepção do espaço como elemento articulador da narrativa:

Não deve o estudioso do espaço, na obra de ficção, ater-se apenas à sua visualidade, mas observar em que proporção os demais sentidos interferem. Quaisquer que sejam os seus limites, um lugar tende a adquirir em nosso espírito mais corpo na medida em que evoca sensações.

“Pela primeira vez senti que algo estranho, novo, ia acontecer”, essa é uma passagem que explica o pacto ficcional formado pelo leitor, narrador e texto literário. Já estamos na metade do conto, e até agora o leitor está preso ao texto por impressões causadas pelos efeitos que a linguagem cria. O narrador recupera a fidelidade do leitor, gerando a expectativa de que algo acontecerá e será narrado nas linhas a seguir; afinal, percebemos que a mudança de cenário e de sentimento revela que o narrador não caminha pela Paris que conhece. A narração prossegue: "Tive a impressão de que fazia frio, de que o ar se adensava, de que a noite, minha noite bem-amada, pesava sobre meu coração" (MAUPASSANT, 2004, p. 222); trata-se, aqui, da transfiguração da noite amada para a noite aterrorizante.

A confusão mental do narrador é interrompida por uma marcação temporal: "Nunca tinha visto Paris tão morta, tão deserta. Puxei meu relógio, eram duas horas" (MAUPASSANT, 2004, p. 222). A constatação do relógio funcionando é algo importante para a criação da atmosfera de "A noite", representa 
mais do que passagem do tempo, o seu funcionamento revela a vida que transcorre, apesar da angústia; é o que Ceserani (2006) ressaltará como o “detalhe”, importante para a construção da atmosfera fantástica. É importante notarmos que, após a marcação temporal, o narrador parte para uma profunda imersão na escuridão da noite e de seu pesadelo, a ausência de tempo linear aponta para o desaparecimento da ordem natural do próprio tempo, como já afirmamos.

O que, até então, era descrito como uma fonte de vida passa a ser descrito como "nunca tinha visto uma noite tão escura", o que é seguido por "firmamento de nuvens, cerrado como a imensidão, afogara as estrelas e parecia descer sobre a terra para liquidá-la” (MAUPASSANT, 2004, p. 222). A noite, de onde o narrador tirava sua força, passa a exauri-lo, atormentando suas percepções, causando mais confusão, é o que percebemos quando alguns personagens "passantes" cruzam o caminho desse homem que vaga por Paris, assim ocorre com o bêbado e com o cocheiro. A inserção da fala indireta de uma mulher, na rua Drouot, pode ser inferida como uma possível mensageira que não é considerada pelo narrador: "Ei, cavalheiro, escute” (MAUPASSANT, 2004, p. 222).

À medida que o trajeto do narrador percorre os arredores de Paris, percebemos a passagem do tempo, pela interpelação ao catador de trapos, pelo apagar dos lampiões de gás. A transfiguração da noite pode ser percebida pelo viés da mudança noite-amor para a noite-pavor e por percebermos que a noite que está sendo descrita não pertence ao conjunto das noites conhecidas pelo narrador.

Os parágrafos seguintes constituem o ápice da agonia em que o narrador se encontra: "Vamos para o Halles', pensei, 'pelo menos lá encontrarei vida”, (MAUPASSANT, 2004, p. 223). São essas passagens, carregadas de simbologia, usando recursos mínimos, que prendem o leitor diante do presságio da morte do narrador. Ao proferir "vamos", quem é a outra pessoa que acompanha o narrador? É ele e seu duplo, seu inconsciente, o eu-em-pesadelo e o eu-consciente? É a morte, cuja presença foi simbolizada pelo frio e adensamento do ar, anunciados pelo narrador há vários parágrafos, que o acompanha? Novamente, trazemos a perspectiva teórica de Ceserani (2006) e os núcleos temáticos da literatura fantástica: o duplo. O teórico ressalta que esse recurso (o duplo) é amplamente usado na literatura e no teatro desde a Antiguidade: "Entretanto, no fantástico, o tema é fortemente interiorizado, e ligado à vida da consciência, das suas fixações e projeções" (CESERANI, 2006, p. 83). O duplo, se estiver presente na narrativa de Maupassant, manifesta-se interiorizado, nos labirintos do inconsciente, entre o real e o ficcional. 
A partir desse momento da narrativa, o leitor tem a impressão de que a afirmação "O que amamos com violência sempre acaba nos matando", no início dessa segunda parte (divisão sugerida neste artigo), se concretizará, pois há a construção da ausência de vida. A sutileza da linguagem cria no leitor essa nova possibilidade, não se trata da presença da morte, mas da ausência de vida. O cão que rosna revela uma Paris fantasmagórica: "Toda Paris dormia, com um sono profundo, apavorante [...] ruas solitárias e negras, negras, negras como a morte. [...] Nem um passante, nem um retardatário, nem um vagabundo, nem um miado de gato apaixonado. Nada" (MAUPASSANT, 2004, p. 223). A ausência de vida está presente também nas ruas de Paris: sem iluminação, iguais, tornam-se sombrias, sem pedestres, elevando a experiência do estranho, do inquietante.

Novamente o relógio, como recurso narrativo metafórico, surge. Para sentir que ainda está vivo, nessa tensão crescente em que juntos estão o narrador, o leitor e a noite, o tique-taque do relógio é simbólico, faz companhia até que, quem sabe, o dia nasça. O relógio está "vivo" segundo afirma o narrador e o conto prossegue. A alucinação desmascara o narrador, que afirma: "esperando que enfim o dia raiasse". O estranhamento surge, pois a primeira parte do conto é arquitetada sobre a lassidão e fadiga do dia em oposição ao amor e à força da noite. A noite deixa de ser um espaçotemporal entre o crepúsculo e o nascer do sol e se torna um estado absoluto do narrador.

O narrador continua em seu delírio, caminhando um "tempo infinito" (MAUPASSANT, 2004, p. 223), novamente a linguagem simula a confusão do narrador: caminhar pressupõe grandeza de espaço, não grandeza de tempo. É quando o narrador admite, finalmente, sentir medo: "Tive medo!" (MAUPASSANT, 2004, p. 223). A indeterminação do tempo acompanha a dissolução do espaço na escuridão.

A ausência de vida marca a transição da segunda para a terceira parte do conto de Maupassant (2004, p. 223): "O mercado estava deserto, sem um ruído, sem um movimento, sem um carro, sem um homem, sem um molho de legumes ou um ramo de flores - as barracas estavam vazias, imóveis, abandonadas, mortas!". A tensão aumenta quando o narrador admite ser invadido por um pavor.

A terceira parte, na divisão sugerida neste artigo, mostra ao leitor um possível recobrar de consciência do narrador, ao tentar sair desse pesadelo em que se encontra: "Fui embora" (MAUPASSANT, 2004, p. 223), e, novamente, o relógio, símbolo da vida e do passar do tempo, surge: parado, ressaltando a 
ausência de vida e a perturbação da ordem natural das coisas. Ausência também marcada pela linguagem: "Mais nada, mais nada, mais nenhum arrepio na cidade, nenhum clarão, nenhum vestígio de som no ar. Nada! Mais nada!" (MAUPASSANT, 2004, p. 223). A ausência de vida é potencializada pela brisa glacial, anunciando a névoa, o obscuro, o soturno... a morte. O "nada" é apresentado como núcleo temático da literatura fantástica por Ceserani (2006), muitas vezes, segundo o teórico, niilismo e loucura se juntam, amplificando as experiências de leitura literária.

Os mínimos recursos usados na construção do conto, apontado por Calvino, são explicitados no penúltimo parágrafo:

O Sena ainda corria? Quis saber, encontrei a escada, desci... Eu não ouvia a torrente encapelando sob os arcos da ponte... Mais degraus... depois, areia... lama... depois a água... molhei o braço... ele corria... frio... frio... frio... quase gelado... quase seco... quase morto (MAUPASSANT, 2004, p. 223).

O uso das reticências, o olhar quase cinematográfico, quadro a quadro, a descrição da confusão e hesitação das sensações, a gradação do movimento, quase em câmera lenta, para que assim o leitor possa acompanhar o narrador nesse abaixar de corpo e de tensão, fazem com “mínimos recursos” o máximo da apreensão.

É como se o corpo do narrador e o corpo do leitor entrassem em sintonia, um economizar de energia para preservar-se: o caos do pesadelo em que o narrador se encontrava até "chegar" às margens do Sena e atingir assim o equilíbrio, em que a tensão se dispersa, e, possivelmente, o narrador fica semiconsciente.

O conto se constrói na quase ação, no quase passeio, na quase morte do narrador. Nessa quase morte, o narrador declara: "E senti perfeitamente bem que nunca mais teria força para subir de novo... e que ia morrer ali... eu também, de fome, de cansaço, e de frio" (MAUPASSANT, 2004, p. 224). É importante reparamos, novamente, que o narrador não divaga sozinho, mais uma vez as ambiguidades entre consciente e inconsciente, vida e morte, ficção e realidade se encontram. Para Todorov:

O fantástico implica portanto não apenas a existência de um acontecimento estranho, que provoca hesitação no leitor e no herói; mas também numa maneira de ler, que se pode por ora definir negativamente: não deve ser nem "poética", nem "alegórica". 
É a maneira de ler que faz com que o pacto ficcional se reafirme parágrafo após parágrafo. $\mathrm{O}$ universo ficcional criado pelo narrador faz com que a hesitação do leitor o obrigue a prosseguir na leitura, nas palavras de Todorov (2017, p. 36): "é a hesitação que lhe dá vida”. O leitor acompanha a narração situado na intersecção entre o real e o fantástico. Além da transgressão do tempo, a atmosfera insólita no conto de Maupassant é intensificada pela construção de um espaço ficcional híbrido.

O texto literário de Maupassant, o conto "A noite", permite ao leitor experienciar a linguagem, fazer do signo verbal um elemento estético que mergulha no próprio homem, na sua interioridade, revelando que a ficção se alimenta do nosso medo e da nossa experiência. Leitor e personagem ficam imóveis, às margens do Sena, à espera de Caronte, quem sabe, que venha o barqueiro e leve os náufragos, leitor e narrador, para a outra margem do rio.

\section{CONSIDERAÇÕES FINAIS}

A leitura de um clássico já foi justificada por Italo Calvino de muitas maneiras. Ao findarmos esta análise, as palavras de Calvino (1993, p. 205) nos ajudam a compreender a dimensão da obra de Maupassant e a multiplicidade de olhares e saberes possíveis de serem produzidos a partir de um texto:

A realidade do mundo se apresenta a nossos olhos múltipla, espinhosa, com estratos densamente sobrepostos. Como uma alcachofra. 0 que conta para nós na obra literária é a possibilidade de continuar a desfolhá-la como uma alcachofra infinita, descobrindo dimensões de leitura sempre novas.

"A noite" é um texto literário que demanda habilidades e estratégias de leitura complexas. Firmar o pacto ficcional entre o leitor, o autor e a obra, a tríade indissolúvel segundo Candido (2000), é um procedimento que requer verticalização da leitura, além da fruição e do prazer estético que o conto de Maupassant possa proporcionar.

Desfolhar a alcachofra, ler as entrelinhas, mergulhar na interioridade do indivíduo é o que confere ao conto de Maupassant múltiplas possibilidades de leitura. Polissemia e universalidade permitem que uma obra permaneça, além da noite estrelada, quando, finalmente, nasce o dia. 


\section{Neither owl, nor lark}

\section{Abstract}

In this article, we propose to go through Calvino's (2004) statement when he organized the selection Fantastic tales from the 19th century, presenting Guy de Maupassant's tale "The night" as: "An example of Fantastic obtained with minimal resources". Todorov's (2017) and Ceserani's (2006) studies help us understand Maupassant's text's architecture, revealing how the theoretical characteristics appear, in this case, diluted in the literary text.

\section{Keywords}

Tale. Fantastic. XIX century.

\section{REFERÊNCIAS}

BARBIERI, C. Arquitetura literária: sobre a composição do espaço narrativo. In: BORGES FILHO, O.; BARBOSA, S. (org.). Poéticas do espaço literário. São Carlos: Claraluz, 2009. p. 105-126.

CALVINO, I. Por que ler os clássicos? Tradução Nilson Moulin. São Paulo: Companhia das Letras, 1993.

CALVINO, I. (org.). Contos fantásticos do século XIX. São Paulo: Companhia das Letras, 2004.

CANDIDO, A. A literatura e vida social. In: CANDIDO, A. Literatura e sociedade. 4. ed. São Paulo: Nacional, 2000.

CESERANI, R. O fantástico. Tradução Nilton Cezar Tridapolli. Curitiba: Editora UFPR, 2006.

LINS, O. Lima Barreto e o espaço romanesco. São Paulo: Ática, 1976.

MAUPASSANT, G. de. A noite. Tradução Rosa Freire D’Aguiar. In: CALVINO, I. (org.). Contos fantásticos do século XIX. São Paulo: Companhia das Letras, 2004.

TODOROV, T. Introdução à literatura fantástica. Tradução Maria Clara Correa Castello. São Paulo: Perspectiva, 2017. 